The man continued in a state of great emaciation for a considerable time, necessity imposing upon him a very spare diet, and no means being taken by hi; medical attendant to supply him with anything beyond the two shilling's and sixpence per week, and the bread allowed by the union. Everything that he took continued for some weeks to pass through the opening, but upon persevering in the use of lavements his bowels at length acted partially in the natural way. At the same time, it may be observed, that the use of lavements was left to be suggested by a non-professional individual who casually visited him.

Such is the treatment which this poor fellow bas received under this union medical contractor, and but for the kind suggestions of those medical gentlemen who had visited him from time to time, from motives of curiosity, as well as from feclings of compassion, he must bave been lost; and it is only to be regretted that the latter were not aware of the case at a time when efficient relief might have been afforded to him. It may be added, that no means have been taken, even to the present time, to accelerate the closing of the fistulons openings, and there he remains in just the same state as he has been in for the last twelve weeks, - the gentlemen in the neighbourhood, who are competent to undertake the case, declining to interfere, as their interference would cause the man's pay to be withdrawn by the guardians.

[This statement refers to what has taken place between the 27th of March and the last month.]

CASE 2.-William Abbot, of Woodbrook, in the parish of Kington, labourer, on the 24th of December last received a severe wound on the back of his right hand, from getting it entangled in the wheel of a timber carriage, the whole of the integument being torn off, and the hand otherwise frightfully bruised and lacerated. He went immediately to the medical officer of the union who sewed up some part of the wound, and dressed it, telling the man to come again on the next day but one. The man went as directed, and was told that the part was "going on well, and that it need not be undone," and he was desired to come again in two days. At the expiration of the two days he kept his appointment, stating that his arm was much swollen, and that his hand was exceedingly painful, to which the only reply he obtained was, "What would you have said if it had been as big as your body?" He requested to have it dressed, but could not prevail on the medical officer to accede, and he was compelled to return to his home as he left it. On the seventh day after the accident he went again, and represented the very painful condition of the wound, pointing out that matter was oozing from beneath the bandage in every direction, and that it was so offensive that his wife could not bear him in the house. The only reply which he received was, "Well, I cannot attend to you now," and he was at length compelled to get it dressed elsewhere as well as he could.

The man was laid up, however, nine weeks with the injury, and when he had been at his work three weeks this humane individual called, for the first time, to inquire "what had become of him?"

[** The foregoing statements have been authenticated by the writer in a private note to the Editor.]

\section{DUBLIN COLLEGE OF SURGEONS.}

\section{To the Editor of The LANCET.}

Sir :-As a letter signed "A Licentiate," published in your last number, contains, amongst other strictures, an allusion to a recent regulation of the Dublin College of Surgeons, which may be misunderstood by those most interested in the matter, " the class of Irish students," may I beg your insertion of the following explanation, It is true that the College have virtually refused the lectures as delivered by the master of the chartered Dublin Lying-in Hospital, by requiring of candidates for their licence, attendance on a course of lectures on midwifery, delivered in a medical or surgical school, to meet which bye-iaw the pupils attending this Institution are free to $\mathrm{my}$ late assistant, Dr. Murphy's, lectures, to be delivered in the adjoining school, Marlborough-street, They have not, however, disfranchised the Dublin Lying.in Hospital; on the contrary, they have rendered attendance on practical midwifery, either in it, or in some other of the institutions which are recognised by their body, imperative, in future, on such as may be candidates for their licence. I am, Sir, your obedient servant, Evory Kennedy, Master, Dublin Lying-in Hospital.

Nov. 13, 1837.

SPECIMEN OF MEDICAC APPOINTMENTS IN THE NEW UNIONS.

\section{To the Editor of THE LANCET.}

SIR :-If the following statement will be of any service in procuring redress of medical grievances from boards of guardians, you are at liberty to make what use you please of it; we pledge ourselves to prove its truth.

The Linton Union is divided into three 
districts, one of which (the Balsham) contains an agricultural population of 3614 , more than two-thirds of whom are paupers during illness. This our father and ourselves have attended for fifty years, with the exception of one parish. At the beginning of September the Guardians advertised for tenders, and we offered to find all the paupers every species of surgical and medical aid, with the exception of midwifery and trusses, for $90 l$. per annum. Our tender was the only one sent in, yet it was rejected, and a person employed who has been a resident in this neighbourhood but a short time, does not live in the district, has also the care of the Linton district, and who thus has to attend fifteen parishes, the united population of which is 7902. During our attendance there was no complaint made against us, so that it is perfectly clear that the only reason of our dismissal was to save the paltry sum of $15 l$, which is the difference between our tender, and what $\mathrm{Mr}_{\mathrm{r}}$. Howard receives. $\mathrm{He}$ has to pass our doors to visit most of the parishes, one of which is eight miles from his house. We remain, Sir, yours, \&c.

\section{John Prince.}

Balsham, Cambridgeshire,

Thonas Prince.

Nov. 11, 1837.

THE CHOLERA IN AFRICA.

The cholera has just broken out in the Dey's Hospital at Algiers. On the 11th of October 17 cases, 9 deaths were reported. At Bona, where the epidemic has been prevailing for some time, the number of cases on the 17th October had amounted to 328 , the deaths to 180. One of the most curions points in the history of the Asiatic cholera is, perhaps, the steady proportion of deaths to cases which may be observed to have occurred in all parts of the world, and in all climates. 'This fact proves how very little has as yet been done in the treatment of the disease.

M. Donné, who has lately paid considerable attention to the composition of the humran fluids, thus expresses the composition of milk :-

"Mils is a fluid holding in solution lactic sugar, salts, a small quantity of fatty matter, and of caseum ; and, in suspension, a number of globules composed of butter, which are of various sizes, and solnble in ether.

"The first milk, or colostrum, contains, in addition, ptrticular bodies, which $M$. Donné designates "granular ;" these latter do not disappear entirely before the end of the first month after delivery: they sometimes, however, continue beyond that time. In cases of abscess of the namma, the milk sometimes contains pus, and may contain blood."-French Iancet

\section{AUTOPSY OF GENERAL DAMRE- MONT.}

The Comte de Damremont was killed by a cammon-ball at the seige of Constantine, in Octuber last. 'The report of the post-mortem examination of the body states, that on the left side of the body, above the last false rib, there appeared a large opell wound, about seven inches across, which gave exit to a considerable portion of epiploon, and a mass of large intestine, which was torn across. The stomach was also perforated by the ball, which latter had passed through the diaphragm, and base of the lungs, and then made its exit at the region of the back, having broken into minute fragments the $9 \mathrm{th}, 10 \mathrm{th}$, and 11 th vertebra. The wound at this side of the body presented a cutaneous opening five inches in length.-French Lancet, Oct. $28 \mathrm{th}, 1837$.

\section{TO CORRESPONDENTS.}

Tyro omitted to give the particulars of the examination to which he has made reference in his letter.

Unfortunately, in the instance to which $A$ Student has adverted, he has formed an erroneous impression.

We have received a letter from $A$ S $u b$ scriber, in defence of the late proceedings at the Westminster Hospital. We ask our correspondent, Is it our fault if the hospital cannot afford more leeches? As to the surgical treatment of ruptured urethra, we are as well conversant with it as our correspondent.

Communications have been received from H. S. P., from Dr. Sorley, Mr. Selvyn, and J. $T$.

On the subject of the communication of J.T., a strong remonstrance should be made to the party concerned; should this fail, recourse may then be had to publicity.

Mr. Gibson, of Glasgow, has communicated to us a case of Asiatic cholera, which occurred in that city on the 26th of August last. It was successfully treated by him with stimulants, and full doses of calomel and opium. Want of space prevents us from inserting the case in full.

Several communications, reports, and papers, are unavoidably postpoued. Among them are a lecture by Dr. Wallace, with engravings, on the Skin of the Negro, and a paper read at the Phrenological Society, by Dr. Elliotson, entitle 1, " On the Ignorance of the Discoveries of Gall, evinced by recent Physiological Writers." Also, hospital reports, and several letters.

Novel and Bold Treatment in ApoPLEXY.-In a Manual just published for Apothecaries' Hall, by a learned member of the College of Surgeons, we find it gravely recommended, in cases of apoplexy, to bleed from the jugular vein, and carotid artery! 